\title{
Impact of a Local Host on the Success of an International Assignment
}

By

\author{
Marian van Bakel \\ Marinel Gerritsen \\ Jan Pieter van Oudenhoven
}

This longitudinal study examined whether contact with a local host in the Netherlands positively impacts on the adjustment and performance of "Western" expatriates with English or French as their first language. Thirty-one expatriates were put in contact with a Dutch host with whom they would have regular contact over nine months; another 30 similar expatriates would have no contact with a host. After a five-month period of contact with a host, there was a positive impact on interaction adjustment. The results also indicated that expatriates who valued the contact highly derived more benefit from it. Contact with a host seems to be especially worthwhile for expatriates who have to deal with host nationals on a daily basis. (0) 2011 Wiley Periodicals, Inc.

\section{Introduction}

t may take time before expatriates are able to meet company expectations because they have to adjust not only to new work roles but also to new living environments. The more time this takes, the greater the costs for the organization (Black \& Stephens, 1989, p. 529). An unsuccessful international assignment is not only costly in terms of financial compensation and lost expenses for relocation and training, but also in terms of consequences for future business success of the organization (Van der Bank \& Rothmann, 2006, p. 34). In addition, a failed assignment can lead to indirect costs such as disappointment and a loss of self-esteem for the expatriate (Black, Gregersen, \& Mendenhall, 1992, p. 12; Mendenhall \& Oddou, 1985, p. 39; Tung, 1987, p. 117). Although expatriate failure rates may not be as high as have been claimed in the past (e.g., Harzing \& Christensen, 2004), it is clear that job changes across national borders are difficult and warrant as much research attention as domestic turnover.

There are many different ways in which a company can support its employees before, during, and after an international assignment. These range from offering 
cross-cultural training or preparatory visits to acquaint the expatriate with the country of assignment to keeping in touch with the expatriate during the assignment to assuring the expatriate that he or she has a job after returning home. In this article, a specific type of support is introduced-namely, putting expatriates in touch with a host national. The aim of this article is to examine whether this type of support can improve the success of an international assignment.

The period immediately after arriving in a new country is full of uncertainty and anxiety. Moving home or job are important stressors in life. In the case of an international assignment, the stress is exacerbated due to the fact that one also moves to another country. The expatriate needs to learn to cope with this important life event. Coping is defined as "constantly changing cognitive and behavioral efforts to manage specific external and/or internal demands that are appraised as taxing or exceeding the resources of the person" (Lazarus \& Folkman, 1984, p. 141). The resources that people have (for example, social skills and social support) influence the way in which they cope with the demands (Lazarus \& Folkman, 1984, p. 179).

Research has shown the importance of informal relationships in dealing with uncertainty (Albrecht \& Adelman, 1987, p. 19). Social networks are crucial in the management of cross-cultural transition. An additional complication, when transferred to another country, is that part of the social network that could provide support in such situations is left behind (Adelman, 1988, p. 190). New social ties need to be formed. This can be done by drawing on two important sources of social support in the new country: fellow expatriates and host-country nationals.

Contact with host nationals has long been said to reduce the degree of difficulty an expatriate faces (Landis, Bennett, \& Bennett, 2004, p. 302). This ties in with contact theory (e.g., Allport, 1954) that posits that interpersonal contacts between individuals from different cultures should reduce prejudice (Pettigrew \& Tropp, 2006) and result in understanding and adjustment (Hanvey, 1979). These suggestions are supported by the results of a number of studies. Furnham and Bochner (1986, p. 251) suggested that expatriates who have "some intimate contact" with host nationals seem to be more satisfied in their private and professional lives, and are more successful than expatriates who do not have this kind of contact. Brewster and Pickard (1994) showed that a high level of interaction with host nationals is associated with easier adjustment to the environment. The support of hostcountry nationals is also found to be a predictor of spousal adjustment (Shaffer, Harrison, Luk, \& Gilley, 2000, p.
30). These findings were confirmed in a recent study by Podsiadlowski, Spieß, Stroppa, and Vauclair (2008), who found that of the two sources of support available in the host country, only support of host nationals was related to psychological well-being and overall satisfaction with the sojourn. Their finding that support from people from the home country did not influence these outcomes corroborates the importance of establishing a new social network in the host country.

Expatriates often find it difficult, however, to make contact with host nationals. Through the many expatriate clubs and associations, especially numerous in popular expatriate destinations, one mainly meets other expatriates. Therefore, it is not surprising that expatriates tend to receive more support from fellow nationals than from host nationals (Johnson, Kristof-Brown, Van Vianen, De Pater, \& Klein, 2003, p. 284). This focus on contact with fellow expatriates can even be negative. Parker and McEvoy (1993) show that a great amount of contact with fellow expatriates is correlated negatively with adjustment, and Geeraert, Demoulin, and Demes (2008) have recently found that "any" social support was positive at the start, but that the co-national expatriate "bubble" had a negative effect in the long run.

\section{Effect of a Host on the Success of an International Assignment}

Ward, Bochner, and Furnham (2001, p. 43) consider a cross-cultural transition as a significant life event that brings new forms of intercultural contact. Two important models that describe how the confrontation with these new situations can be dealt with, and where a host can provide assistance, are the stress and coping model and the culture learning model.

The stress and coping model focuses on, among other things, the importance of social support for psychological adjustment (Ward et al., 2001). Albrecht and Adelman (1987, p. 19) define social support as verbal and nonverbal communication between recipients and providers that reduces uncertainty about the situation, the self, the other, or the relationship, and functions to enhance a perception of personal control in one's life experience. Wang (2002, p. 324) states that social support can consist of giving care, love, information, technical assistance, and tangible help. The new situation of the expatriate poses certain demands that could trigger a crisis when resources and capabilities are insufficient. Social support is an important resource to cope with uncertainty (Wang, 2002).

Adelman (1988) divides the social network into strong ties such as family and friends, and weak ties such 
as the bus driver and the hairdresser. Strong ties, in particular, will be left behind in the home country when one moves abroad. A local host in the new country can partially fill this gap. Initially, the host will be a weak tie when the contact is still new, but this relationship can develop into a strong tie. The host can provide social support for the expatriate, which can help him deal better with the uncertainty and anxiety caused by working and living in a foreign country.

The culture-learning model posits that contact with host nationals can help expatriates to learn about cultural rules and conventions and result in a smoother sociocultural adjustment (Ward et al., 2001). Host nationals are an important source of information about the host culture, and contact with host nationals is, therefore, a prerequisite for culture learning to take place (Furnham \& Bochner, 1986, p. 15). Caligiuri and Lazarova (2002) have investigated whether socialization and interaction of female expatriates with colleagues and host nationals had an influence on their cross-cultural adjustment. It appeared that the more interaction a female expatriate had with host nationals, the more she learned culturally appropriate norms and behavior. It is plausible that this mechanism could also work for expatriates who are put in touch with a host.

In summary, a host can offer social support and also help expatriates to learn about cultural differences and practical matters in the foreign country. It is plausible that this will add to the adjustment of the expatriate, which in turn could have a positive effect on their work performance. Our research model is depicted in Figure 1. This article will now turn to a more detailed discussion of adjustment and performance, which together will be called the success of an international assignment.

\section{The Success of an International Assignment}

Studies on the success of an international assignment, also called expatriate effectiveness, focus often on crosscultural adjustment. An international assignment is an important life change with an intercultural component (Ward et al., 2001, p. 43), and cultural differences seem

\section{FIGURE 1 Expatriate Contact With a Host and the Success of the International Assignment}

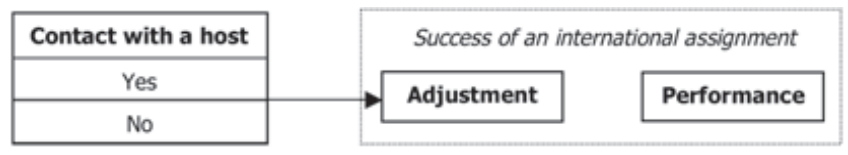

to be an important source of problems for expatriates (Bennhold-Samaan, 2004, p. 376). Many of these studies assume that adjustment impacts the performance of the expatriate. Mol, Born, and Van der Molen (2005, p. 341) posit, however, that "causal relationships between such variables [e.g., adaptation] and job performance are more often assumed than empirically investigated." Since, from the point of view of the sending organization, optimal performance of the expatriate is the ultimate goal of the international assignment, it is important, according to them, to include performance measures in research examining the determinants of successful international assignments.

Although performance should be a central concept in research on the success of international assignments, it should not be the only focus. After transition to a foreign country, expatriates enter an unfamiliar environment with which they have to become familiar in order to be able to function well. As Wang (2002, p. 333) puts it: "it is obvious that if the expatriate can adjust to the local environment and [reach a high level of psychological well-being], he or she will be able to develop his or her full potential to perform well." Adjustment is necessary not only in the workplace, but also in private life. Since these two domains are neither isolated nor independent of each other, spillover might occur (Takeuchi, Yun, \& Tesluk, 2002).

A number of studies show that cross-cultural adjustment is positively related to performance (Bhaskar-Shrinivas, 2005, p. 273; Caligiuri, Phillips, Lazarova, Tarique, \& Burgi, 2001; Cui \& Awa, 1992). It is therefore important to include both cross-cultural adjustment and performance in studies concentrating on the determinants of the success of international assignments. In the following paragraphs, these two concepts will be elaborated upon.

\section{Cross-Cultural Adjustment}

The concept of cross-cultural adjustment has been extensively studied in both the acculturation and the expatriation literatures. For this concept, other terms are often used, such as adaptation, acculturation, and accommodation (Haslberger \& Brewster, 2008; Searle \& Ward, 1990, p. 450). In this article, the term is simply shortened to adjustment.

The earliest theories on sojourner adjustment focused on the negative effects that were often experienced. An important concept is the U-curve (Lysgaard, 1955; Oberg, 1960), which consists of an initial honeymoon phase, a crisis (culture shock), a transition stage where one starts to feel better again, and a final period of adjustment. Culture shock was seen as an occupational 
disease (Oberg, 1960, p. 177). Nowadays, models of adjustment have evolved from the "pseudo-medical" model of culture shock, for which only limited empirical support exists (Black \& Mendenhall, 1991; Ward, Okura, Kennedy, \& Kojima, 1998), to models that emphasize learning experiences and management of stress-provoking life changes (Ward et al., 2001, p. 45).

Both the acculturation literature and the expatriation literature conceptualize adjustment as a multidimensional concept. The leading model in the expatriation literature is that of Black (1988), which consists of three dimensions: general adjustment, interaction adjustment, and work adjustment. This model has been tested in a number of studies, which has resulted in the firm establishment of these three dimensions. The model has, however, also received some criticism, notably with regard to conceptualization and the actual items of the measuring instrument. For instance, Thomas and Lazarova (2006, p. 251) point out that the scale was not constructed on a sound theoretical base.

Soon after Black published his model, Searle and Ward (1990) reviewed two decades of publications on the contact between expatriates, immigrants, refugees, and sojourners with the host culture and the subsequent effect it had on their adjustment. On the basis of this review, they proposed a distinction between psychological and sociocultural adjustment in order to distinguish between the "feelings of well-being and satisfaction" and the "ability to 'fit in' and negotiate interactive aspects of the new culture" (Searle \& Ward, 1990, p. 450). These two facets are widely used in acculturation research but are not as popular as Black's model in the expatriation literature (Thomas \& Lazarova, 2006, p. 251).

Although Ward's model is theoretically sounder than Black's model, Thomas and Lazarova (2006, p. 252) identify some limitations, such as the actual measurement of the two facets of adjustment. For example, Ward and colleagues conceptualize psychological adjustment as well-being and satisfaction but measure it through an established depression inventory. In order to explain that some studies do not find a separate set of predictors for each type of adjustment, as originally proposed by Ward and colleagues (e.g., Searle \& Ward, 1990, p. 453), Oguri and Gudykunst (2002) suggest that it makes a difference whether psychological adjustment is measured in a negative way (as depression) or in a positive way (as satisfaction). For example, the predictor "host-language fluency" is only related to psychological adjustment when it is conceptualized in a positive way (satisfaction), and not when it is measured as depression (Oguri \& Gudykunst, 2002, p. 592).
Thomas and Lazarova (2006, p. 252) conclude in their review of expatriate adjustment and performance that both the Black model and the Ward model contain useful aspects and insights for the study of adjustment. In our research project, we therefore used both models to complement each other.

\section{Performance}

For an organization to survive and realize its goals, it is important that its employees have a reasonable level of job performance. Job performance is a set of behavior patterns that are relevant for the goals of the organization (Campbell, 1990). It is a central concept in human resource management (HRM) literature: the aim of selection procedures is to predict performance, while other organizational interventions are implemented to measure or improve job performance (Arthur \& Bennett, 1997, p. 142). The criterion of job performance, however, has not been conceptualized structurally in domestic HRM, nor in international HRM (Ones \& Viswesvaran, 1997, p. 75).

A change of jobs brings about uncertainty and ambiguity even when it occurs in the same city or company. When the job change includes a different country, another level of complexity is added because factors such as cultural differences come into play. These circumstances add to the constraints that can hinder-or stimulate-job performance (Spector, 2000, p. 234).

There are two basic methods for assessing job performance. Objective measures result from companies tracking the behavior of employees, such as turnover and absenteeism. Subjective measures are based on ratings by supervisors or other people who should have an overview of the job and the job performance in question (Spector, 2000, p. 79). For managers, 360-degree feedback has become a frequently proposed measure to evaluate performance from more than one perspective-not only from the perspective of the supervisor, but also from the perspective of the peers and subordinates (Spector, 2000). In addition, a multiple-perspective evaluation will reduce the rating biases and rating errors that every individual almost unavoidably makes.

Most of these methods are, however, not easily available for researchers who are interested in expatriate job performance. Performance management systems at headquarters are often not applicable to the specific expatriate's environment. Supervisors may be too far away to be able to evaluate expatriate performance, or there may be other practical constraints. It is also possible that there are cultural differences in performance assessment. Abe and Wiseman (1983, p. 62) found, for example, that Japanese and Americans had different perceptions of the 
concept of intercultural effectiveness. The expatriation literature therefore has often used other criteria to measure performance, simply because it has been difficult to assess expatriate performance in the way one would do in domestic situations. An often-used criterion in the expatriation literature is early return, which focuses on behavioral job strains; however, it sheds only a limited light on the actual performance of the expatriate because it only takes into account extreme cases. The criteria that aim to take a broader view on job performance focus on psychological job strains such as psychological withdrawal. Although these criteria do not measure actual turnover, they do include expatriates who do not function well but remain on their assignment. For example, Shaffer and Harrison (1998, p. 91) use "psychological withdrawal" (thoughts and plans to quit the assignment) as a criterion for the success of an international assignment. Similarly, Caligiuri (2000) and Garonzik, Brockner, and Siegel (2000) use the term "desire to prematurely terminate the assignment." Other criteria that have been used to measure expatriate job performance are adjustment and job attitudes such as commitment and job satisfaction (Thomas \& Lazarova, 2006).

Church (1982) suggests that in order to gain a reliable picture of job performance, it is better to use a variety of measuring instruments rather than just one instrument. Therefore, to avoid bias as much as possible, and to get a complete picture of the performance of the expatriates in this study, we use more than one instrument to measure performance.

\section{Method}

Our research project examines whether contact with host nationals is indeed beneficial for the success of an international assignment. In order to test this, expatriates in the Netherlands were put in contact with a Dutch host with whom they had regular contact during nine months; they were compared to expatriates who had no Dutch host. At the beginning of the research, and after five and nine months, the expatriates filled in questionnaires to assess the success of their international assignment in terms of adjustment and performance. In this article, we have only reported on the impact of a host in the first five months; the analysis of the final questionnaire has only recently been started.

\section{Participants}

Our longitudinal study was set up specifically to test whether a host contributes to the success of an international assignment. Half of the participants were randomly

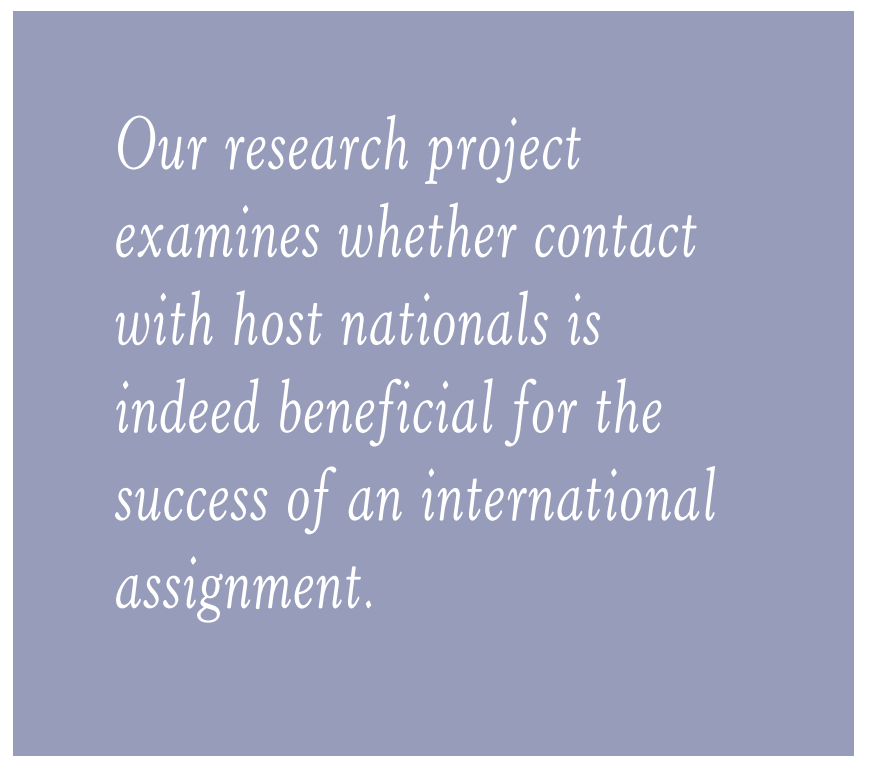

assigned to the host condition; the other half were put in a control group without a host. Expatriates could participate only if they met the following five criteria:

- $\quad$ had arrived in the Netherlands in the past year;

- were from Europe, North America, Australia, or New Zealand;

- $\quad$ spoke English or French as their first language;

- were on a temporary job assignment of at least ten months; and

- did not have a Dutch partner.

This study focused on "Western" expatriates, because transitions to relatively nearby cultures can pose unexpected problems. The similarities between these cultures and the Netherlands are often only superficial, and this may lead to the unrealistic expectation that the cultures do not differ at all (Martin \& Harrell, 2004, p. 318). This lack of awareness of cultural differences can also create difficulties for expatriates. It is important to study transitions to nearby cultures, because it is just these types of assignments that are on the rise (Brewster, 1995, p. 61). Of the expatriates, $54 \%$ had their partner with them on their assignment, $12 \%$ had a partner back home, and $34 \%$ did not have a partner. More than half of the expatriates were male $(57 \%)$. The age of the expatriates ranged from 23 to 56 years old $(\mathrm{m}=35.2)$, and $46 \%$ had children.

The expatriates were generally highly educated $(89 \%$ college level or beyond); $90 \%$ spoke Dutch poorly. 
French (31\%), American (25\%), and British (22\%) were the top three nationalities represented in the sample. The expatriates had been in the Netherlands an average of 6.4 months when they started in the project; $92 \%$ of the expatriates had been in the Netherlands for less than a year.

\section{Instruments}

\section{Adjustment}

In order to measure psychological and sociocultural adjustment, we used the following instruments:

- Psychological adjustment: Following Van Oudenhoven, Mol, and Van der Zee (2003, p. 160) we operationalized psychological adjustment through "positive" concepts such as psychological and physical health and satisfaction with life. Psychological health $\left(\alpha^{\text {baseline }}\right.$ $=.83 ; \alpha^{5}$ months $\left.=.85\right)$ consisted of nine items on a scale of 1 (none of the time) to 5 (all of the time). The scale started with the phrase: "How much of the time during the past four weeks" and was followed by items such as: "have you felt calm and peaceful" or "did you feel worn out." Physical health $\left(\alpha^{\text {baseline }}=.74\right.$; $\left.\alpha^{5 \text { months }}=.68\right)$ was assessed by two questions assessing the general health on a scale of one (poor) to five (excellent) and the amount of time the physical or emotional health interfered with social activities $(1=$ none of the time to $5=$ all of the time). To complete the picture, respondents reacted to four statements such as "I seem to get sick a little easier than other people" and "My health is excellent" on a scale of 1 (definitely false) to 5 (definitely true). Satisfaction with life scale $\left(\alpha^{\text {baseline }}=.85 ; \alpha^{5}\right.$ months $\left.=.86\right)$ was composed of five items on a scale of 1 (strongly disagree) to 5 (strongly agree), such as "In most ways my life is close to my ideal" and "If I could live my life over, I would change almost nothing."

- Sociocultural adjustment: As this aspect of adjustment focuses on the quality of the interaction with people in the host country, a short version of the 41-item Social Support List Interaction (Van Sonderen, 1993) was used, as in the study of Van Oudenhoven et al. (2003). Fifteen items on a scale of 1 (seldom or never) to 4 (very often) assessed the number of times respondents experienced that people were "affectionate towards you," "ask you for help," or "blame you for things" ( $\left.\alpha^{\text {baseline }}=.85 ; \alpha^{5 \text { months }}=.81\right)$.

- General, work, and interaction adjustment were measured by 14 items on a scale of 1 (unaccustomed) to 7 (accustomed), very similar to the measure devel- oped by Black and Stephens (1989). The first seven items regarded general adjustment (e.g., "living conditions in general"), followed by four items focusing on interaction adjustment (e.g., "socializing with host nationals"). The final three items assessed work adjustment through items such as "specific job responsibilities" and "supervisory responsibilities." Reliability coefficients for all three variables were generally very high (general adjustment: $\alpha^{\text {baseline }}=$ $.83 ; \alpha^{5}$ months $=.79$; interaction adjustment: $\alpha^{\text {baseline }}=$ $.87 ; \alpha^{5 \text { months }}=.95 ;$ work adjustment: $\alpha^{\text {baseline }}=.94 ; \alpha^{5}$ months $=.85)$.

\section{Performance}

Performance was measured by two instruments.

- Desire to terminate the assignment: The instrument of Caligiuri (2000) was used to determine the expatriates' desire to terminate the assignment. The instrument contains three items on a scale of 1 (no, definitely not) to 5 (yes, definitely). A sample item is: "Would you like to terminate this expatriate assignment early?" ( $\alpha^{\text {baseline }}$ $=.83 ; \alpha^{5 \text { months }}=.82$ )

- Assessment of own performance $\left(\alpha^{\text {baseline }}=.66 ; \alpha^{5}\right.$ months $=$ .73) was measured with four items that asked the expatriates to assess their own performance on a scale of 1 (poor) to 5 (excellent) in areas such as "ability to get along with others" and "ability to complete assignments on time” (Parker \& McEvoy, 1993).

\section{Covariates}

We also examined the effect of the quality of the contact with the host, because it not only indicates whether the strategy of putting expatriates in contact with a host was successful in itself, but also whether the expatriates benefited more from the contact with a host when they rated the contact as sufficiently high. The expatriates with a host were therefore asked to provide a score on a scale of 1 (lowest) to 10 (highest) when judging the contact with their Dutch host.

\section{Procedure}

The participants in our study were solicited through a variety of channels: international schools, expatriate associations and (online) networks, expatriate fairs, and information about the project on websites, in company newsletters, in local newspapers-even social networking sites. It is therefore likely that the sample is somewhat biased toward the more active type of expatriate who has an interest in what is going on in his or her new environment. 
The expatriates could register through the website www.let.ru.nl/m.v.bakel. They were then asked to fill in the first questionnaire of the project as well as a form with questions (e.g., about hobbies) that could help to match the expatriate with a suitable host. Hosts were volunteers not working for the same company as the expatriate, and they were mainly found through our personal networks and through snowball sampling. The registration procedure for the hosts was similar to that of the expatriates.

Sixty-one participants took part in the study; $31 \mathrm{ex}$ patriates were put in touch with a host (experimental group) and 30 were not (control group). After having filled in the first questionnaire, the participants were told whether they would be put in touch with a host immediately (experimental group) or after nine months, when the research project had finished (control group). We tried to find a suitable host within a reasonable amount of time, matching primarily for place of residence, age, and family situation.

Expatriates in the experimental group were put in touch with their host through an e-mail containing a short introduction to both parties to facilitate the first contact. To monitor the contact during the project, the first author of this article kept in touch with the hosts, rather than the expatriates, in order to minimize the possible effects of contact with the researcher. At the end of the project, the participants in the control group were asked whether they were still interested in being put in touch with a host. If so, they were put in touch with a host using the same procedure as described earlier. They were no longer research subjects and did not have to fill in any more questionnaires.

\section{Data Analysis Strategy}

The effect of a host on the performance and adjustment variables was analyzed using multivariate and univariate analyses of variance with host (yes or no) as the fixed factor. To reflect the development of the dependent variables during the first five months, change scores of the dependent variables were used in the analyses. These scores were obtained by deducting the score of the first assessment (baseline level) from the score of the second assessment (five months). This was done for each of the dependent variables.

\section{Results}

\section{The Success of the International Assignment}

Tables 1 and 2 show an overview of the change scores on the adjustment and performance variables for the experimental group (host) and the control group (no host). In

\section{TABLE 1 Mean Change Scores on Adjustment (Over Five Months) of Expats With or Without a Host}

\begin{tabular}{|c|c|c|c|c|c|c|c|}
\hline \multirow{2}{*}{$\begin{array}{l}\text { Change Scores ( } 5 \text { Months-0 Months) } \\
\text { Adjustment }\end{array}$} & \multicolumn{3}{|c|}{ Host } & \multicolumn{3}{|c|}{ No Host } & \multirow[t]{2}{*}{ Sign. } \\
\hline & $N$ & M & SD & $N$ & M & SD & \\
\hline \multicolumn{8}{|l|}{ Psychological adjustment } \\
\hline Satisfaction with life & 31 & 0.08 & 0.46 & 30 & 0.01 & 0.62 & - \\
\hline Physical health & 31 & -0.34 & 0.58 & 30 & -0.20 & 0.62 & - \\
\hline Psychological health & 31 & 0.16 & 0.36 & 30 & 0.09 & 0.59 & - \\
\hline Sociocultural adjustment & 31 & 0.03 & 0.27 & 30 & 0.01 & 0.39 & - \\
\hline General adjustment & 31 & 0.47 & 0.83 & 30 & 0.87 & 0.92 & - \\
\hline Interaction adjustment & 31 & 0.99 & 1.34 & 29 & 0.25 & 1.82 & $p<.05$ \\
\hline Work adjustment & 30 & 0.31 & 1.05 & 30 & 0.74 & 1.09 & - \\
\hline
\end{tabular}

TABLE 2 Mean Change Scores on Performance (Over Five Months) of Expats With or Without a Host

\begin{tabular}{|l|c|c|c|c|c|c|c|}
\hline Change Scores (5 Months-0 Months) & \multicolumn{3}{c}{ Host } & \multicolumn{3}{c|}{ No host } & \multicolumn{2}{c|}{ Sign. } \\
Performance & N & M & SD & N & M \\
\hline Assess own performance & 30 & 0.03 & 0.41 & 30 & 0.07 & 0.46 & - \\
\hline Desire to terminate & 23 & 0.25 & 0.87 & 21 & 0.22 & 0.55 & - \\
\hline
\end{tabular}


FIGURE 2 The Effect of Contact With a Host on Interaction Adjustment, 1 (Lowest) to 5 (Highest)

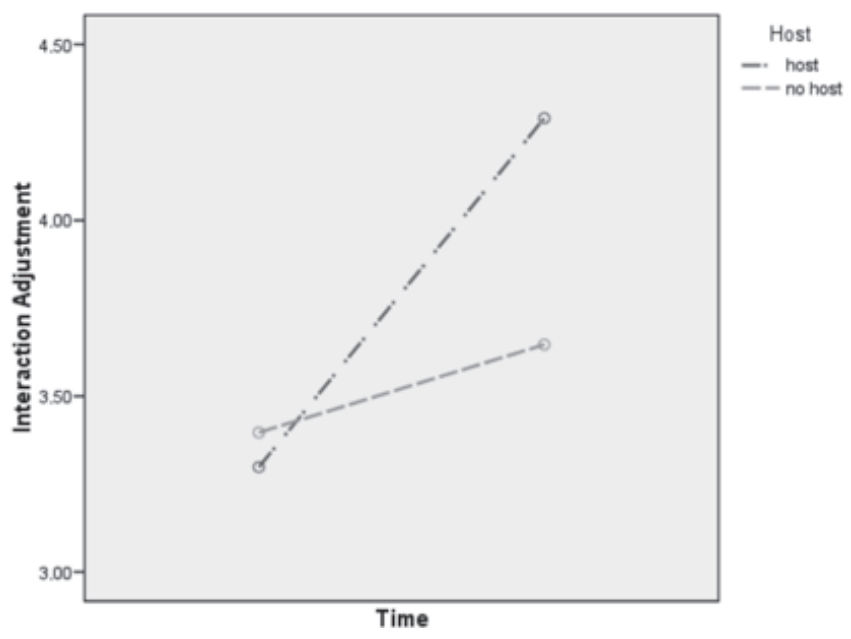

view of the direction of the predictions, differences were tested one-sidedly.

The only variable that shows a significant effect of having a Dutch host is interaction adjustment $(F(1,57)=$ $3.06, p<.05)$. The group with a host has a higher increase on interaction adjustment in the first five months of the contact than the group without a host (Figure 2). The assignment of a local host does not appear to have any significant effects on the other adjustment and performance variables.

\section{Quality of Contact}

For exploratory reasons, we also asked about the quality of the contact with the host; this was done not only because it is important to examine whether the intervention of putting expatriates in touch with a host has worked in itself, but also because the quality of the contact could affect the benefit that is derived from being in touch with a local host. After five months, $70 \%$ of the expatriates rated the contact with the host as sufficient (6 or higher); $59 \%$ scored the contact even as good or very good ( 8 or higher). It can therefore be concluded that more than two-thirds of the interventions with a host were successful according to the participants themselves. The following quote of a Canadian expatriate can serve as illustration:

What did we do? Dinner, walks, museum, dancing, hanging out, etc. Meeting with the host family meant caring, stimulating encounters, and it made me feel welcome and cared for. There was someone to listen to me. It is a very meaningful connection.

We can expect that there is a difference in change in adjustment and performance between expatriates who value the contact with the host as sufficient or higher and expatriates who value the contact as insufficient. Therefore, we have performed $t$-tests for all adjustment and performance variables with the factor quality of contact with host (sufficient, insufficient). The results presented in Table 3 show that quality of contact with the host has an impact on satisfaction with life $(t(28)=-2.20, p<$ $.05)$, psychological health $(t(28)=-2.14, p<.05)$, and physical health $(t(28)=-1.97, p<.05$; one-sided testing) (see Table 3 ). A sufficiently or highly valued contact leads to significantly more positive changes on these variables than an insufficient contact.

These findings indicate a possible moderating effect of the quality of the contact during the first five months when examining the effect of a host on the success of an international assignment. However, these results should be treated with caution in view of the small numbers in both groups.

\section{Discussion}

There was only an effect of a local host on interaction adjustment, one of the three aspects of adjustment of the

TABLE 3 Impact of the Quality of Contact With the Host After Five Months on Change Scores of Satisfaction with Life, Psychological Health, and Physical Health

\begin{tabular}{|c|c|c|c|c|c|}
\hline Dependent Variable & Five Months & $N$ & Mean & SD & Significance \\
\hline \multirow[t]{2}{*}{ Satisfaction with life } & Sufficient & 22 & 0.20 & 0.43 & \multirow[t]{2}{*}{$p<.05$} \\
\hline & Insufficient & 8 & -0.20 & 0.48 & \\
\hline \multirow[t]{2}{*}{ Psychological health } & Sufficient & 22 & 0.22 & 0.35 & \multirow[t]{2}{*}{$p<.05$} \\
\hline & Insufficient & 8 & -0.09 & 0.36 & \\
\hline \multirow[t]{2}{*}{ Physical health } & Sufficient & 22 & -0.20 & 0.54 & \multirow[t]{2}{*}{$p<.05$} \\
\hline & Insufficient & 8 & -0.64 & 0.56 & \\
\hline
\end{tabular}


Black model (Black, 1988). The host probably provides the expatriate with opportunities to come into contact with the local community and, as a result, to learn the Dutch cultural norms and behaviors. This leads to better adjustment when interacting with people from the host country. The results also indicate that the quality of the contact with the host could be important as well. The rating of the contact (sufficient or not) was linked to satisfaction with life, psychological health, and physical health, indicating that high-quality contact with a host can provide more benefits than when the contact has been less appreciated.

\section{Theoretical Implications}

Social support is, in many ways, crucial for the success of an international assignment. It is "one of the primary strategies for coping with the stress of an overseas assignment" (Fontaine, 1986, p. 362). The social networks that can give social support are not always readily available in the host country; they can be left behind in the home country, or, as in the case of an accompanying partner and children, they can also experience stress related to their adjustment to the new country. For these reasons, Fontaine (1996) suggests including social support as a topic in intercultural training. Our study shows that it is possible to increase the amount of social support an expatriate and his/her partner receives on their assignment by putting them in touch with a host. Although personal relationships are inherently difficult to direct, friendships can be developed in this way, as exemplified by the following quote of an American participant:

I think for us it worked because we became friends very quickly; we have a lot in common; we enjoy each other's company a lot and did quite a few things together very early on. In the first few weeks, we met up about twice a week.

\section{Practical Implications}

The results of this research suggest that it is important to consider the goal and context of the international assignment when designing expatriate support programs. Including an intervention such as putting the expatriate in touch with a host is especially important for those expatriates for whom contact with host-national colleagues and customers is an integral part of their job. They could benefit from the social contact with the host to learn better how to deal with the host nationals they encounter in their day-to-day jobs. It should be noted, however, that the present research focused on interactions between
"Western" expatriates and hosts. Future research is needed to determine whether such an intervention could be beneficial as well—or perhaps even more beneficialfor expatriates crossing larger cultural gaps.

Even though our study did not indicate a direct influence of host contact on job performance, contacts with the local community could have other beneficial effects for the company as well. Au and Fukuda's (2002) research on boundary-spanning activities-the amount of cross-boundary information that managers exchange (Au \& Fukuda, 2002, p. 286)—suggests that contacts with locals in general can be profitable, not only for the expatriate but also for the multinational corporation. As boundary-spanning activity is facilitated by an increased diversity of the social network, contact with a host provides extra access to local knowledge. This can be adapted to the global corporate context to benefit the multinational corporation (Hocking, Brown, \& Harzing, 2007).

\section{Limitations and Future Research}

As this research project uses self-report questionnaires, the adjustment and performance variables are subject to common method bias. For this reason, we included several measures of adjustment and performance in the current study. Although the expatriates were randomly assigned to both conditions, and informed of this fact only after they had filled out the first questionnaire, the experimental group (with a host) had a significantly higher score at the baseline level on four of the nine adjustment and performance variables (physical health, psychological health, general adjustment, and work adjustment). This could have led to a possible ceiling effect. In addition, due to the method of soliciting participants, the sample in our longitudinal research might not be representative for the "Western" French- or English-speaking expatriate population in the Netherlands. It is, for example, likely that those expatriates who were interested in connecting with their local community would have signed up more easily for our project than those who were less interested. It could therefore be that these people would also have managed by themselves because they would have made contact with the Dutch in other ways. This might make it more difficult to discern the effect of a host for this particular group than it would be for other expatriates. It is possible that contact with a host is especially beneficial for those expatriates who find it more difficult to make contact with others and who would not readily sign up for such a project. This calls for further research.

The present study offers some indication that the quality of the contact with the host is an important element for 
adjustment. A further avenue of research could be to investigate which aspects of the quality of contact play a part in adjustment. It is possible that a local host would contribute much more to the assignment when they qualify as a strong tie (Adelman, 1988) and have met frequently. Other aspects could be influential as well-for example, the type of contact (instrumental vs. emotional support) or the fit between the expatriate and the host, not only in terms of place of residence, age, and family situation, but also in terms of personality. Also, in this research, the hosts were not trained. Although the first author kept in touch with the hosts to monitor the contact from a distance, one could imagine that a closer monitoring and assistance when the contact is encountering obstacles could further enhance the effectiveness of having a host.

In the present study, the partner has not been taken into account. It might also be that the effect of having a host is more substantial for partners than for the one employed because they often struggle to deal with not having a meaningful job (Punnett, 1997, p. 245) and frequently have a lot of time on their hands.
In addition, it is also possible that the effect of the host will only be seen in the longer term. At the start of the research project, one has to get in touch through e-mail and make the first appointment. Then it takes a while to get acquainted and to establish a frequent contact. Five months may not be enough for a clear effect to show.

\section{Conclusion}

In summary, companies could offer their expatriates support by bringing them in contact with a local host. This seems to be especially worthwhile for those dealing with host nationals on a daily basis. The expatriates themselves express positive reactions about the contact in the openended questions in the questionnaires. These comments range from making daily situations easier to helping to meet Dutch people socially outside the workplace. Future research should determine when and how putting expatriates in touch with a host can optimally contribute to the success of the international assignment.

\begin{abstract}
After receiving her master's degree in international business communication at Radboud University Nijmegen, the Netherlands, Marian van Bakel was a visiting study fellow at the University of Oxford, where she conducted research on the adjustment of Dutch diplomats and their partners in London. She is currently attached to the Centre for PhD Research at Radboud University Nijmegen, where she is writing her PhD thesis on longitudinal research in the field of expatriate adjustment. She also works as a communications consultant at Radboud University Nijmegen Medical Centre and has done extensive voluntary work in the intercultural field for the Young Society of Intercultural Education, Training and Research. Her main research interests are expatriate adjustment and performance, social support, and intercultural communication competence.
\end{abstract}

Prof. Dr. Marinel Gerritsen holds the Christine Mohrmann Chair in the Department of Business Communication Studies at Radboud University Nijmegen. Prior to this, she worked for the government and for several multinational organizations in Europe and she also held positions at a number of Dutch universities and the Royal Netherlands Academy of Arts and Sciences. Her business communication research is primarily focused on the differences between cultures in communication and the impact that this has on intercultural communication. She has also published widely on the sociolinguistic embedding of language variation and change, the use of English as a lingua franca in business contexts, and the interface between English as an international language and the local languages in use.

Prof. Dr. Jan Pieter van Oudenhoven graduated from the University of Leiden in social psychology. He started his career in Latin America as a United Nations Educational, Scientific, and Cultural Organization (UNESCO) associate expert in educational programs for farmers. Since 1976 he has been connected to the University of Groningen as a social and cross-cultural psychologist. His main research interests are international cooperation, individual factors of adaptation of migrants and acculturation, and cross-cultural differences in virtues. 


\section{References}

Abe, H., \& Wiseman, R. L. (1983). Cross-cultural confirmation of the dimensions of intercultural effectiveness. International Journal of Intercultural Relations, 7, 5-67.

Adelman, M. (1988). Cross cultural adjustment: A theoretical perspective on social support. International Journal of Intercultural Relations, 12, 183-204.

Albrecht, T., \& Adelman, M. (1987). Communicating social support: A theoretical perspective. In M. A. T. Albrecht and Associates (Eds.), Communicating social support (pp. 18-40). Newbury Park, CA: Sage.

Allport, G. W. (1954). The nature of prejudice. Cambridge, MA: Perseus Books.

Arthur, W., \& Bennett, W. (1997). A comparative test of alternative models of international assignee job performance. In Z. Aycan (Ed.), Expatriate management: Theory and Research (Vol. 4, pp. 141-172). Greenwich, CT: JAI Press.

Au, K. Y., \& Fukuda, J. (2002). Boundary spanning behaviors of expatriates. Journal of World Business, 37, 285-297.

Bennhold-Samaan, L. (2004). The evolution of cross-cultural training in the Peace Corps. In D. Landis, J. M. Bennett, \& M. J. Bennett (Eds.), Handbook of intercultural training (pp. 363-394). Thousand Oaks, CA: Sage.

Bhaskar-Shrinivas, P. (2005). Input-based and time-based models of international adjustment: Meta-analytic evidence and theoretical extensions. Academy of Management Journal, 48, 257-281.

Black, J. S. (1988). Workrole transitions: A study of American expatriate managers in Japan. Journal of International Business Studies, 19, 277-294.

Black, J. S., Gregersen, H. B., \& Mendenhall, M. E. (1992). Global assignments: Successfully expatriating and repatriating international managers. San Francisco, CA: Jossey-Bass.

Black, J. S., \& Mendenhall, M. (1991). The U-curve adjustment hypothesis revisited: A review and theoretical framework. Journal of International Business Studies, 22, 225-247.

Black, J. S., \& Stephens, G. (1989). The influence of the spouse on American expatriate adjustments and intent to stay in Pacific Rim overseas assignments. Journal of Management, 15, 529-544.

Brewster, C. (1995). Effective expatriate training. In J. Selmer (Ed.), Expatriate management: New ideas for international business (pp. 57-71). Westport, CT: Quorum Books.

Brewster, C., \& Pickard, J. (1994). Evaluating expatriate training. International Studies of Management \& Organization, 24(3), 18-35.

Caligiuri, P., \& Lazarova, M. B. (2002). A model for the influence of social interaction and social support on female expatriates' cross-cultural adjustment. International Journal of Human Resource Management, 13, 761-772.

Caligiuri, P., Phillips, J., Lazarova, M. B., Tarique, I., \& Burgi, P. (2001). The theory of met expectations applied to expatriate adjustment: The role of cross-cultural training. International Journal of Human Resource Management, 12, 357-372.

Caligiuri, P. M. (2000). The big five personality characteristics as predictors of expatriate's desire to terminate the assignment and supervisorrated performance. Personnel Psychology, 53, 67-87.

Campbell, J. P. (1990). Modeling the performance prediction problem in industrial and organizational psychology. In M. D. Dunnette \& L. M. Hough (Eds.), Handbook of industrial and organizational psychology (Vol. 1, pp. 687-732). Palo Alto, CA: Consulting Psychologists Press.

Church, A. (1982). Sojourner adjustment. Psychological Bulletin, 91, 540-572.

Cui, G., \& Awa, N. (1992). Measuring intercultural effectiveness: An integrative approach. International Journal of Intercultural Relations, $16,311-328$.

Fontaine, G. (1986). Roles of social support systems in overseas relocation: Implications for intercultural training. International Journal of Intercultural Relations, 10, 361-378.
Fontaine, G. (1996). Social support and the challenges of international assignments. In D. Landis \& R. Bhagat (Eds.), Handbook of intercultural training (Vol. 2, pp. 264-281). Thousand Oaks, CA: Sage.

Furnham, A., \& Bochner, S. (1986). Culture shock: Psychological reactions to unfamiliar environments. London: Methuen and Co.

Garonzik, R., Brockner, J., \& Siegel, P. A. (2000). Identifying international assignees at risk for premature departure: The interactive effect of outcome favorability and procedural fairness. Journal of Applied Psychology, 85(1), 13-20.

Geeraert, N., Demoulin, S., \& Demes, K. (2008, December 2008). Choose your (international) friends wisely: The impact of intergroup contact during an intercultural sojourn. Paper presented at the Conference of the International Association of Cross-Cultural Psychology, Bremen, Germany.

Hanvey, R. (1979). Cross-cultural awareness. In L. Luce \& E. Smith (Eds.), Toward internationalism: Readings in cross-cultural communication (pp. 13-23). Rowley, MA: Newbury House.

Harzing, A. K., \& Christensen, C. (2004). Expatriate failure: Time to abandon the concept? Career Development International, 9, 616-626.

Haslberger, A., \& Brewster, C. (2008). The expatriate family: an international perspective. Journal of Managerial Psychology, 23(3), 324-346 Hocking, B. J., Brown, M., \& Harzing, A. K. (2007). Balancing global and local strategic contexts: Expatriate knowledge transfer, applications, and learning within a transnational organization. Human Resource Management, 46, 513-533.

Johnson, E. C., Kristof-Brown, A. L., Van Vianen, A. E. M., De Pater, I. E., \& Klein, M. R. (2003). Expatriate social ties: Personality antecedents and consequences for adjustment. International Journal of Selection and Assessment, 11, 277-288.

Landis, D., Bennett, J. M., \& Bennett, M. J. (Eds.). (2004). Handbook of intercultural training (3rd ed.). Thousand Oaks, CA: Sage.

Lazarus, R. S., \& Folkman, S. (1984). Stress, appraisal and coping. New York: Springer.

Lysgaard, S. (1955). Adjustment in a foreign society: Norwegian Fulbright grantees visiting the United States. International Social Science Bulletin, 7, 45-51.

Martin, J. N., \& Harrell, T. (2004). Intercultural reentry of students and professionals. In D. Landis, J. M. Bennett, \& M. J. Bennett (Eds.), Handbook of intercultural training (pp. 309-336). Thousand Oaks, CA: Sage.

Mendenhall, M., \& Oddou, G. (1985). The dimensions of expatriate acculturation: A review. Academy of Management Review, 19(1), 39-46. Mol, S. T., Born, M. P., \& Van der Molen, H. (2005). Developing criteria for expatriate effectiveness: Time to jump off the adjustment bandwagon. International Journal of Intercultural Relations, 29, 339-353.

Oberg, K. (1960). Cultural shock. Adjustment to new cultural environments. Practical Anthropology, 7, 177-182.

Oguri, M., \& Gudykunst, W. (2002). The influence of self construals and communication styles on sojourners' psychological and sociocultural adjustment. International Journal of Intercultural Relations, 26, $577-593$.

Ones, D. S., \& Viswesvaran, C. (1997). Personality determinants in the prediction of aspects of expatriate job success. In Z. Aycan (Ed.), Expatriate management: Theory and research (pp. 63-92). Greenwich, CT: JAI Press.

Parker, B., \& McEvoy, G. (1993). Initial examination of a model of intercultural adjustment. International Journal of Intercultural Relations, 17, 355-379.

Pettigrew, T. F., \& Tropp, L. R. (2006). A meta-analytic test of intergroup contact theory. Journal of Personality and Social Psychology, 90, 751-783.

Podsiadlowski, A., Spieß, E., Stroppa, C., \& Vauclair, M. (2008). Social support for German and New Zealanders on international assignments: A cross-cultural validation and comparison. Paper presented at the Conference of the International Association of Cross-Cultural Psychology. 
Punnett, B. (1997). Towards effective management of expat spouses. Journal of World Business, 32, 243-257.

Searle, W., \& Ward, C. (1990). The prediction of psychological and sociocultural adjustment during cross-cultural transitions. International Journal of Intercultural Relations, 14, 449-464.

Shaffer, M. A., \& Harrison, D. A. (1998). Expatriate's psychological withdrawal from international assignments: Work, nonwork, and family influences. Personnel Psychology, 51, 87-118.

Shaffer, M. A., Harrison, D. A., Luk, D. M., \& Gilley, M. (2000). Spouse adjustment to international assignments: Direct determinants and the moderating effects of coping strategies. Management Research News, 23, 29-31.

Spector, P. E. (2000). Industrial and organizational psychology: Research and practice (2nd ed.). New York: Wiley.

Takeuchi, R., Yun, S., \& Tesluk, P. (2002). An examination of crossover and spillover effects of spousal and expatriate cross-cultural adjustment on expatriate outcomes. Journal of Applied Psychology, $87,655-666$.

Thomas, D. C., \& Lazarova, M. B. (2006). Expatriate adjustment and performance: A critical review. In G. K. Stahl \& I. Bjorkman (Eds.), Handbook of research in international human resource management (pp. 247-264). Cheltenham, UK: Edward Elgar.
Tung, R. L. (1987). Expatriate assignments: Enhancing success and minimizing failure. Academy of Management Executive, 1, 117-126.

Van der Bank, M., \& Rothmann, S. (2006). Correlates of expatriates' cross-cultural adjustment. Management Dynamics, 15(4), 29-39.

Van Oudenhoven, J. P., Mol, S. T., \& Van der Zee, K. I. (2003). Study of the adjustment of Western expatriates in Taiwan ROC with the Multicultural Personality Questionnaire. Asian Journal of Social Psychology, 6, 159-170.

Van Sonderen, F. L. P. (1993). Het meten van sociale steun met de Sociale Steun Lijst-Interacties (SSL-I) en Sociale Steun Lijst-Discrepanties (SSL-D). Een handleiding / Measuring social support with the Social Support List-Interactions (SSL-I) and Social Support List-Discrepancies (SSL-D). A manual. Groningen, The Netherlands: Noordelijk Centrum voor Gezondheidsvraagstukken,

Wang, X. (2002). Expatriate adjustment from a social network perspective: Theoretical examination and conceptual model. International Journal of Cross-Cultural Management, 2(3), 321-337.

Ward, C., Bochner, S., \& Furnham, A. (2001). The psychology of culture shock. London and New York: Routledge.

Ward, C., Okura, Y., Kennedy, A., \& Kojima, T. (1998). The U-curve on trial: a longitudinal study of psychological and sociocultural adjustment during cross-cultural transition. International Journal of Intercultural Relations, 22(3), 277-291. 